\title{
Vascular injury following revision knee arthroplasthy: A case
}

\section{report}

\author{
Yüksel Uğur YARADILMIŞ ${ }^{1 *}$, Mert KARADUMAN ${ }^{1 a}$, Süleyman ALBAYRAK ${ }^{1 b}$, Murat ALTAY ${ }^{1 c}$ \\ ${ }^{1}$ University of Health Sciences, Keçiören Health Practice and Research Center Orthopaedics and Traumatology Department Ankara, Turkey. \\ *Corresponding Author: Yüksel Uğur Yaradılmış. University of Health Sciences, Keçiören Health Practice and Research Center Orthopaedics \\ and Traumatology Department Ankara, Turkey.
}

Received date: February 06, 2021; Accepted date: March 15, 2021 ; Published date: October 7, 2021

Citation: Yüksel U Yaradılmış, Karaduman M, Albayrak S, Altay M (2021) Vascular injury following revision knee arthroplasthy: A case report. J, Surg Case Rep and Imag 4(7); DOI: 10.31579/2690-1897/062

Copyright: () 2021, Yüksel Uğur Yaradılmış, This is an open access article distributed under the Creative Commons Attribution License, which permits unrestricted use, distribution, and reproduction in any medium, provided the original work is properly cited.

\begin{abstract}
Acute arterial occlusions are uncommon complications in total knee arthroplasty (TKA). This complication is seen more in TKA revision surgery, and when appropriate treatment cannot be made, amputation may be necessary. The present case is here presented of a patient applied with TKA revision because of instability following a simple fall one year after primary TKA, and popliteal artery occlusion developed in the early postoperative period. The patient was a 70-year old female not actively working. In the patient history there was deep vein thrombosis in the ipsilateral lower extremity after primary TKA and associated with that, pulmonary embolism. The diagnosis of popliteal artery occlusion, which formed after the revision surgery, was diagnosed with advanced tests in the 3rd hour postoperatively, and in the 4th hour, exploration was made. No arterial active bleeding had been observed intraoperatively. Popliteal thrombectomy were applied of popliteal artery trombosis. Acute arterial occlusion is a rarely encountered complication, but it requires emergency intervention. To prevent the development of acute occlusive disease in revision knee surgery, preoperative evaluation of arterial status is recommended, especially in patients with a history of surgery.
\end{abstract}

Key Words: Knee arthroplasty, revision surgery, acute arterial oclusion, vascular injury

\section{Introduction}

Vascular complications are rarely seen in total knee arthroplasty (TKA), and injuries are classified as (i) iatrogenic vascular injury, (ii) artery occlusion, and (iii) pseudoaneurysm [1]. While there is a low risk of popliteal artery penetrating injuries, iatrogenic vascular injury is seen at the rate of $0.003 \%$ [2,3]. Although popliteal artery occlusion following TKA is seen more often than iatrogenic injuries, the rate has been shown to be $0.03 \%-0.2 \%[4,5]$ and the rate of chronic vascular insufficiency after TKA is estimated to be $2 \%$ [6]. Although vascular injuries are seen at a low frequency, a vascular injury seen during prosthesis surgery is a nightmare situation for orthopaedic surgeons, and the condition seen may cause amputation and even mortality [7]. As TKA is now used at younger ages and because of longer life expectancy, there has been seen to be an increase in the need for revision surgery over the years [8]. Due to the more extensive debridement in revision knee arthroplasty (RKA) and because of large defects, there is more contact with soft tissue. Therefore, in major surgery such as RKA, it is natural that vascular injuries can be seen more often [8]. However, there are few case reports of RKA vascular injuries, or they have been presented within studies that have examined TKA $[1,9]$.
When there arterial occlusions are diagnosed late, the surgical interventions become more complex and the rates of failure increase. Conservative treatments are very limited in the treatment procedures and surgical intervention includes thrombectomy and bypass grafting [10]. The patient presented in this paper was applied with revision surgery because of aseptic loosening following primary TKA, acute popliteal arterial occlusion developed, the decision for surgery was taken early, thrombectomy was performed and successful results were obtained.

\section{Case presentation}

Written informed consent was obtained from the patient's parent. A 70year old female presented on 02.11.2018 with the complaints of pain and not feeling confident in the right knee, which had been ongoing for one month. Three years previously the patient had undergone TKA in another centre for a diagnosis of gonarthrosis. There was a history of a simple fall 11 months after the TKA operation, after which the complaints started and gradually increased. RKA surgery was planned because of instability and the patient was admitted to our clinic.

The patient had height of $154 \mathrm{~cm}$, weight $70 \mathrm{~kg}$, and body mass index (BMI) was calculated as $29.5 \mathrm{~kg} / \mathrm{m}^{2}$. There was a 25 -year history of hypertension and 3 years previously the patient had undergone coronary 
angiography. There was a stent and minimal tricuspid valve insufficiency. The patient had no history of smoking or alcohol consumption. There were no findings of cerebrovascular disease or peripheral vascular dysfunction. In the physical examination, movement of the right knee was painful and there was instability in the coronal plane. No increase in temperature, redness or swelling were observed.

In the preoperative laboratory tests, blood values including platelet count, $\mathrm{PT}$, and aPTT, were within the normal range. Sedimentation and CRP values were normal. On the basis of the physical examination and the laboratory tests, aseptic loosening was considered. RKA surgery was planned for the patient because of aseptic loosening and instability and the patient was admitted to our clinic.

The revision surgery was performed on 19.11.2018. The patient was positioned supine, and under spinal anaesthesia, the tournquet pressure was raised to $280 \mathrm{mmHG}$. The total tourniquet duration was 70 mins. In the intraoperative evaluation an AORI 3 defect was observed (Figure 1).
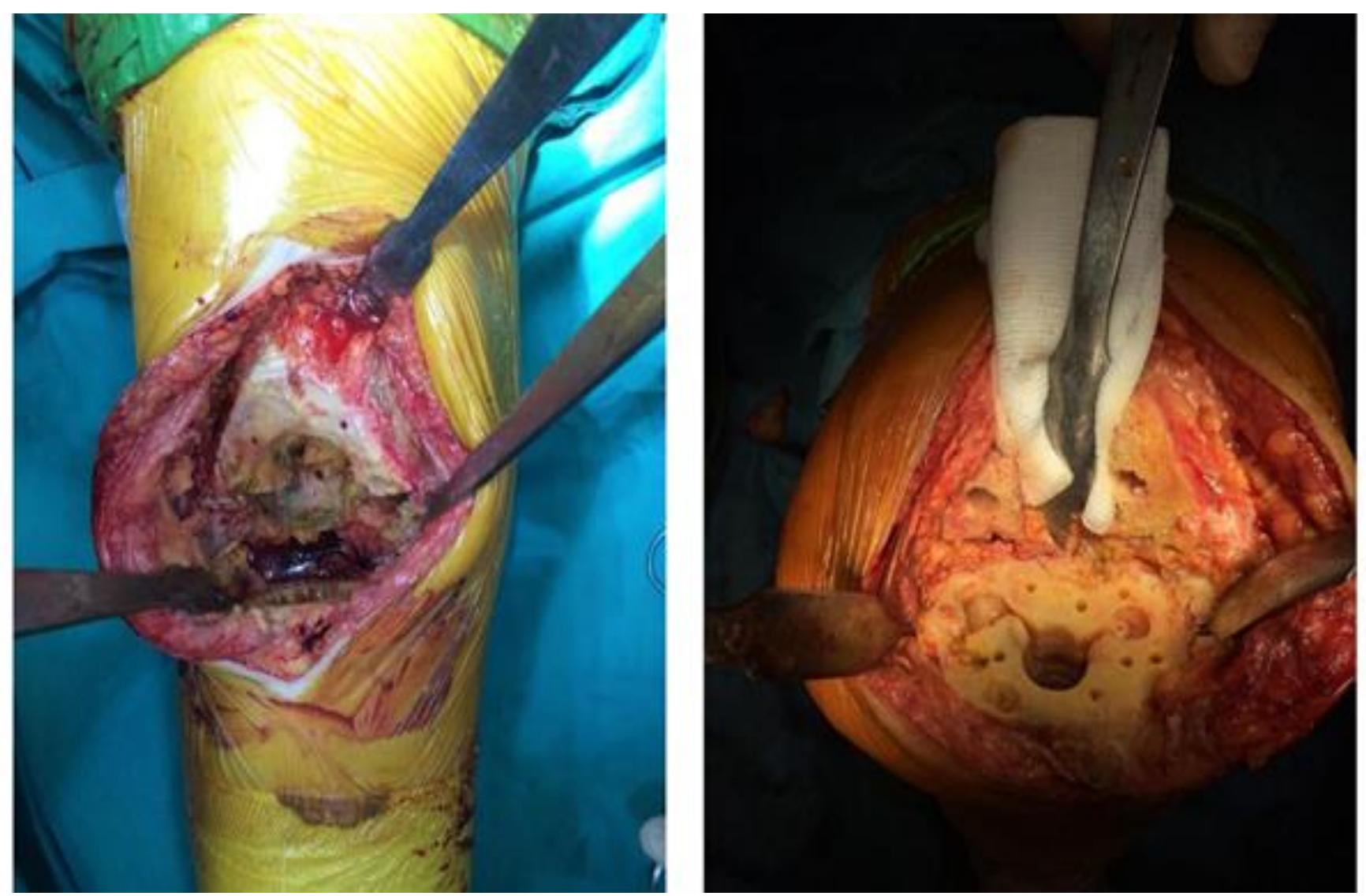

Figure 1: Intraoperative AORI Type 3

Intraoperative frozen material was sent for examination, and was evaluated as acute inflammation. Following the appropriate cuts for bone implantation, treatment was made with a CCK design implant (NexGen RH Knee, Zimmer, Warsaw, IN, USA). After closure of the joint, the tourniquet was deflated. A total of $400 \mathrm{cc}$ fluid was collected in the drain in the first 30 mins. Passive pressure was obtained and followed up.

In the postoperative 2nd hour, pain, paresthesia and paleness developed in the right foot of the patient. In the physical examination, the dorsalis pedis pulse was felt to be filiform. In the tests applied, the hemogram was determined as $8.6 \mathrm{mg} / \mathrm{dl}$. As $900 \mathrm{cc}$ total fluid was in the drain in the $3 \mathrm{rd}$ hour, advanced tests were planned. On the CT angiography, there was seen to be no blood flow in the anterior tibialis artery and at the level of the popliteal artery trifurcation and at $2 \mathrm{~cm}$ proximal of the popliteal trifurcation, and filling of the posterior popliteal artery $3 \mathrm{~cm}$ distal of the popliteal artery trifurcation could not be explained radiologically (Figure 2). 


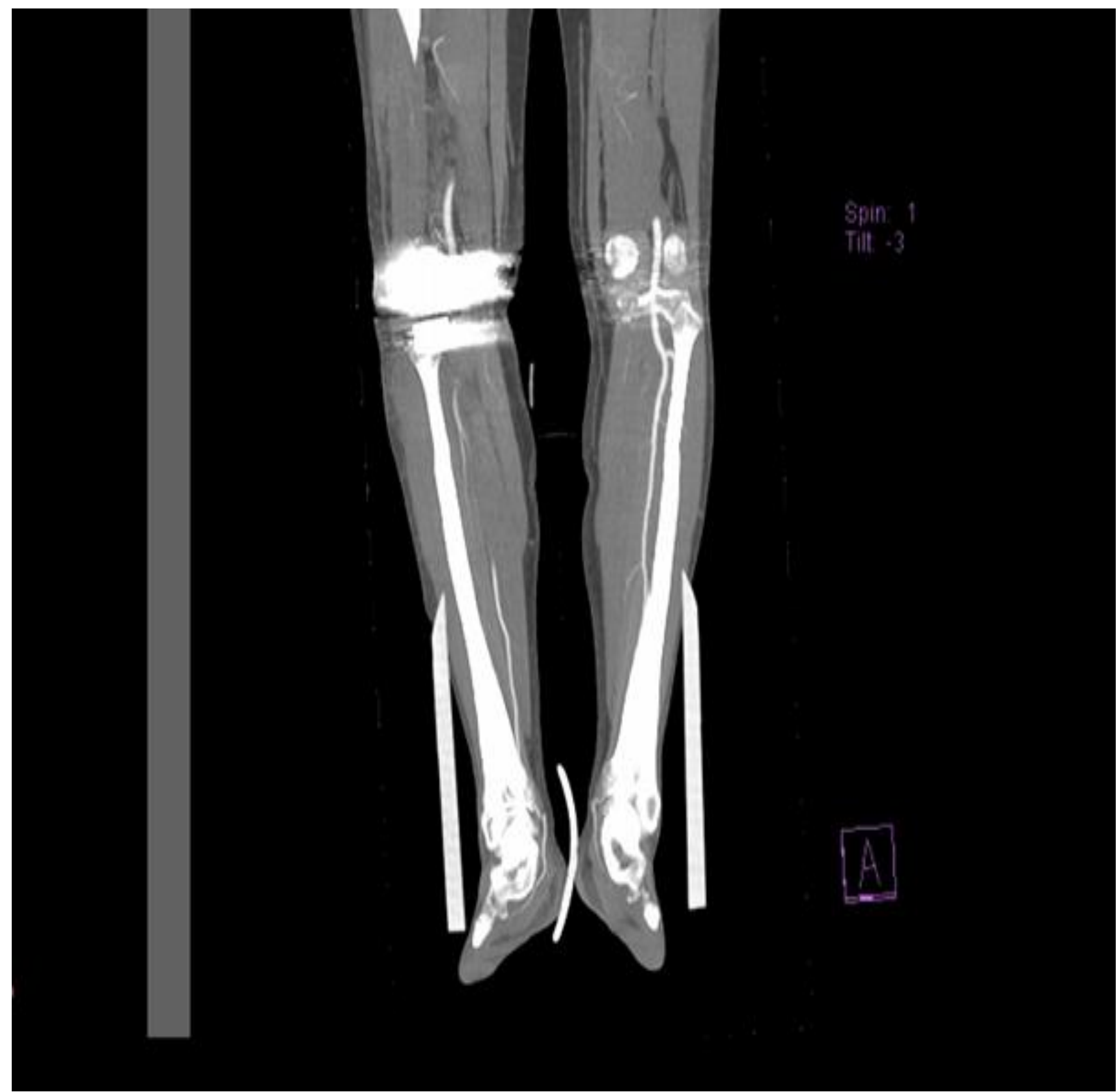

Figure 2: Blood flow in the CT radiography

Emergency exploration was planned as a result of the severe clinical and radiological findings. In the postoperative 4 th hour, the patient was readmitted for surgery for exploration together with a microsurgery specialist.

\section{Surgical procedure}

The patient was positioned prone. The posterior of the knee was opened with a lazy-S incision. No active arterial bleeding was observed in the exploration. The popliteal artery was then evaluated in detail. Occlusion was seen $4 \mathrm{~cm}$ proximal of the popliteal artery bifurcation, and arterial dilatation proximal of the occlusion. Thrombus was observed in the popliteal artery (Figure 3). 


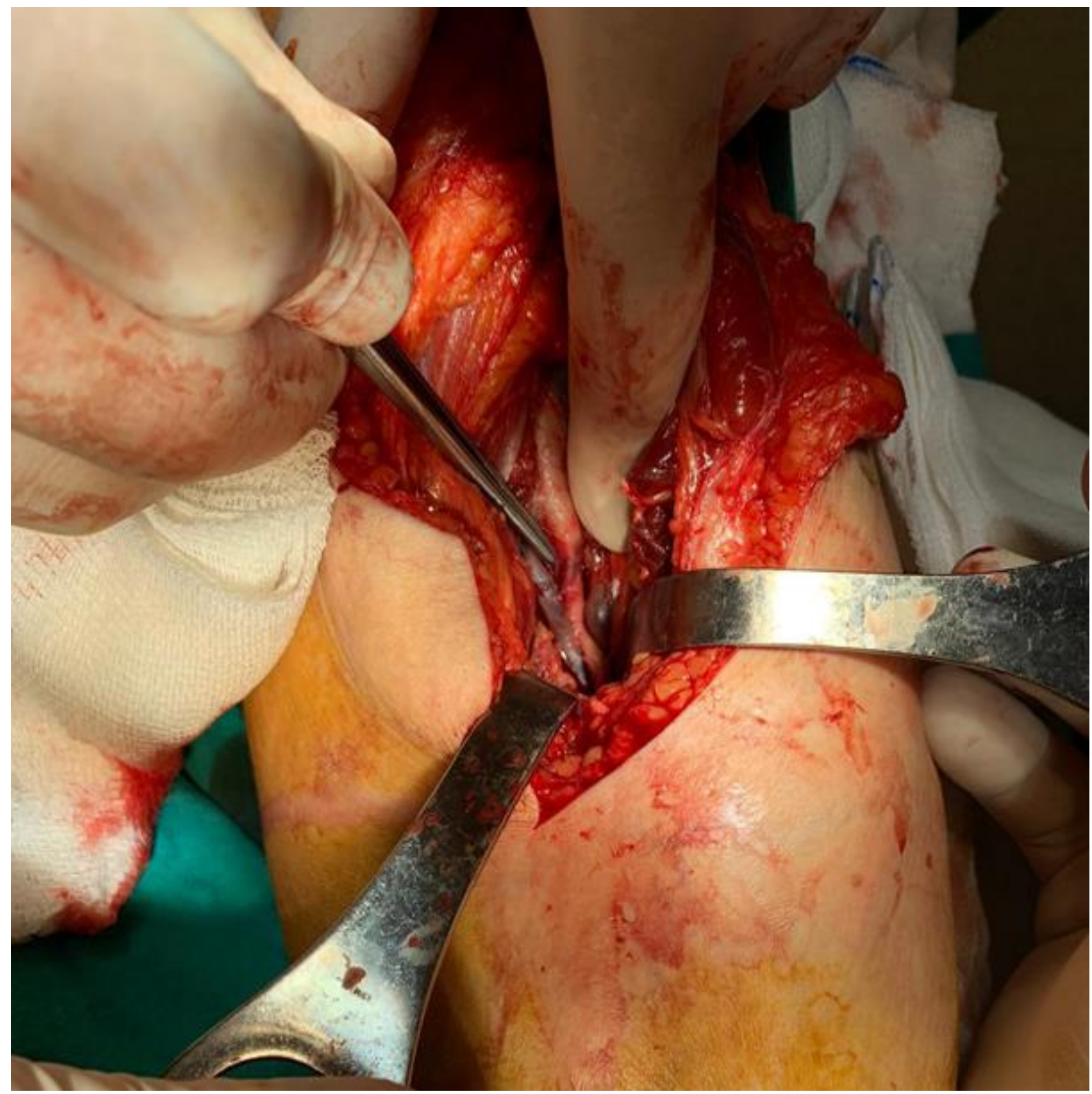

Figure 3: Posterior approach in the knee and popliteal arter occlusion on behind of prothesis

Thrombus was considered, and open thrombectomy was applied proximal of the stasis with the Fogarty catheter. The vascular damage was evaluated again after the thrombectomy. Peripheral pulses were palpated. After confirming blood flow with Doppler, the surgery was terminated.

\section{Follow-up}

The patient was followed up first in the Intensive Care Unit for 2 days. When the vital signs and hemogram were observed to be stable, the patient was transferred to the orthopaedics and traumatology ward, where follow up continued for 7 days. A total of 3 units of blood were transfused: 1 unit preoperatively, 2 units postoperatively. A control radiograph was taken on postoperative day 1 (Figure 4). 

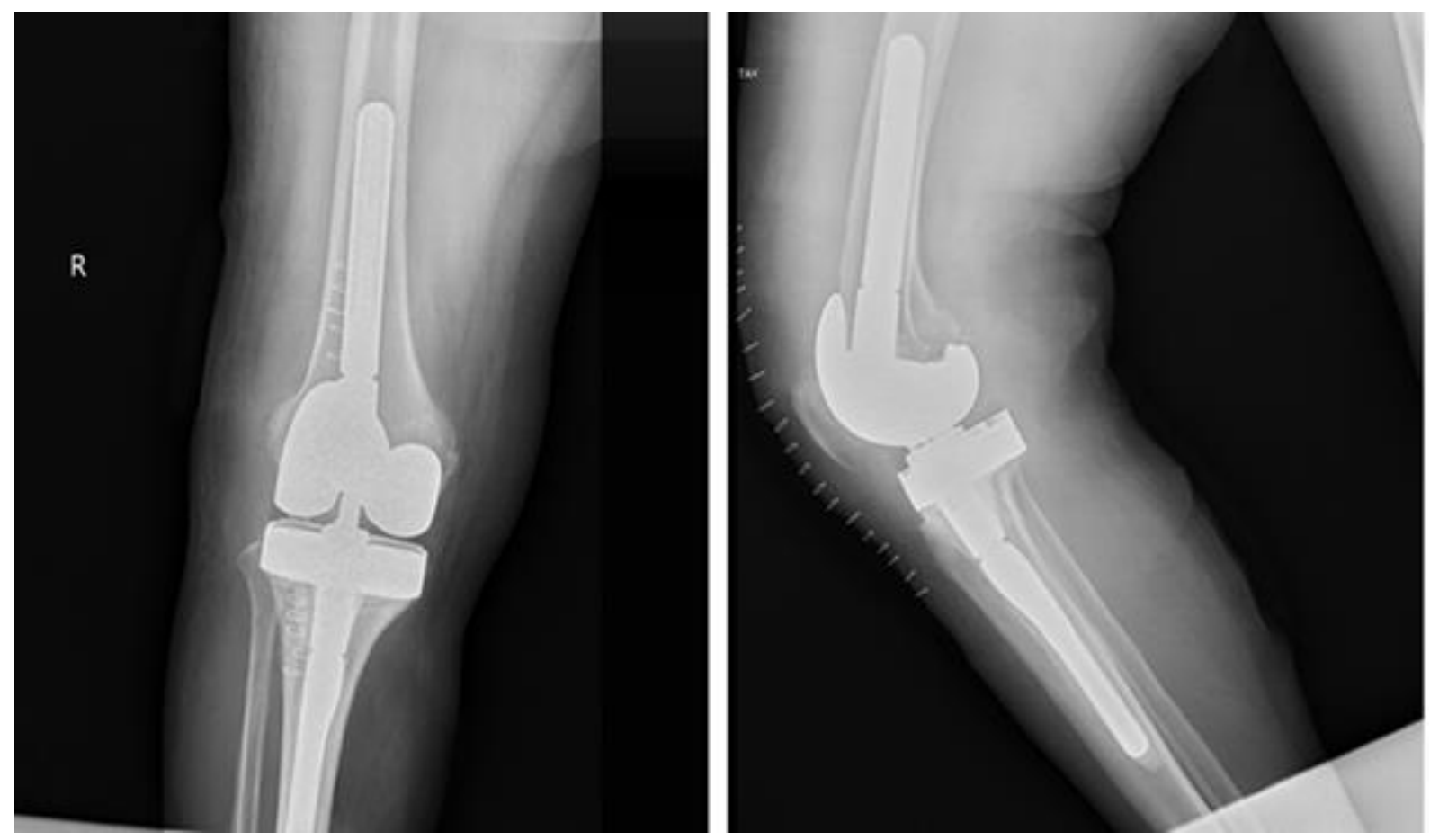

Figure 4: Postoperative antero-posterior and lateral graphy

On the 4th day of follow up, the patient was mobilised. With a CPM device, joint range of motion reached $90^{\circ}$ on the 6th day. The patient was discharged on the 7th day. At the final follow-up examination, the WOMAC score was 84 and joint range of motion was $100^{\circ}$. Currently, at approximately 1.5 years since the operation, minimal paresthesia persists in the right foot. The patient can now walk without any assistive device, can go up and down stairs and describes the knee as pain-free.

\section{Discussion}

Although arterial occlusion is rarely seen, in a study of 31 patients who developed acute arterial occlusion after TKA, it was reported that amputation was necessary in 11 cases $(35.5 \%)$ [11]. Patients must be routinely examined in the early period, and in the postoperative period, severe pain and paresthesia in the ipsilateral extremity should be warnings in respect of vascular injury, and when there is paleness, coldness, and no pulse, advanced tests are necessary [3].

A total of 3018 TKA and 225 RKA patients treated in our clinic since 2012 were examined and there was a single knee arthroplasty patient observed with vascular injury, giving a frequency of $0.03 \%$ of all knee arthroplasties and $0.4 \%$ of RKA. In a similar study, Rand et al examined 9022 patients, and reported that acute artery occlusion developed in 3 patients after TKA $(0.033 \%)$ [4]. In another study by Calligaro et al of 4097 TKA patients, 7 cases $(0.17 \%)$ of acute arterial occlusion were reported [5].

Arterial occlusions often occur with the formation of thrombosis as the result of a traumatised calcified vessel. The presence of peripheral vascular disease, the use of a tourniquet in calcified femoral and popliteal arteries, and manual reduction of flexion contractures $[12,13]$ constitute a risk for plaque rupture and embolisation. Other risks include the presence of cancer, a history of arterial aneurysm, and revision surgery [14].

Emergency thrombectomy is the first option in treatment, but if removal of the thrombus is not possible, surgical bypass is an alternative approach.
In a study by Green and Allen, of revascularisations applied 8 hours after popliteal artery blood flow ceased, amputation was reported to be necessary in $86 \%$ [15]. This demonstrates the necessity for rapid revascularisation in treatment.

In the current case, acute arterial occlusion was observed with the serious symptoms of pain at rest and paresthesia. Emergency thrombectomy was selected as treatment. The decision for surgery in the current case was made at approximately the 4th hour. When revascularisation is delayed, amputation may be required, but in the current case there was no need for amputation. With appropriate physiotherapy, the current patient obtained a high WOMAC score.

\section{Conclusion}

Acute arterial occlusion is a rarely encountered complication, but it requires emergency intervention. The risk of developing arterial complication increases when there is a history of various operations and especially revision TKA.

\section{Reference}

1. Papadopoulos DV, Koulouvaris P, Lykissas MG, Giannoulis D, Georgios A. Et.al (2015) Popliteal artery damage during total knee arthroplasty. Arthroplast DOI:10.1016/j.artd.2015.06.001

2. Dua A, Zepeda R, Hernanez FC, Igbadumhe AA, Desai SS. (2015). The national incidence of iatrogenic popliteal artery injury during total knee replacement. Vascular;23(5):455-458. DOI:10.1177/1708538114552464

3. Li Z, Xiang S, Bian YY, Feng B, Zeng R. (2019). Diagnosis and Treatment of Arterial Occlusion after Knee Arthroplasty: The Sooner, the Better. Orthop Surg.;11(3):366-372. DOI:10.1111/os.12494

4. Rand JA, (1987). "Vascular complications of total knee arthroplasty.Report of three cases,"Journal of Arthroplasty; vol. 2, no. 2, pp.89-93. 
5. Calligaro KD, Delaurentis DA, Booth RE, Rothman RH, Savarese RP. (1994). "Acute arterial thrombosis associated with total knee arthroplasty," Journal of Vascular Surgery; vol. 20, no. 6, pp. 927-932.

6. Inomata K, Sekiya I, Otabe K, et al. (2017). Acute arterial occlusion after total knee arthroplasty: a case report. Clin Case Rep;5(8):1376-1380. DOI:10.1002/ccr3.1075.

7. Naresh KS, Chapman J, Rawlins I. (1998). Vascular injuries in total knee arthroplasty. J Arthroplasty ;13(2): 211.

8. Behnke NM, Cui Q, Orndorff D. (2007). Late presentation of a mycotic popliteal artery pseudoaneurysm in the setting of a revised total knee arthroplasty complicated by both prior infection and periprosthetic fracture: a case report, Annals of Vascular Surgery; vol. 21, no. 4, pp. 519-524.

9. Tsujimoto R, Matsumoto T, Takayama K, et. al. (2015). Acute popliteal artery occlusion after revision total knee arthroplasty. Case reports in orthopedics.
10. Troutman D, Dougherty M, Spivack A, Calligaro K. . (2013). Updated strategies to treat acute arterial complications associated with total knee and hip arthroplasty. J Vasc Surg; 58(4):1037.

11. Matziolis G, Perka C, Labs K. (2004). Acute arterial occlusion after total knee arthroplasty., Archives of Orthopaedic and Trauma Surgery; 124:2. 134-136.

12. Smith DE, McGraw RW, Taylor DC, Masri BA. (2001). Arterial complications and total knee arthroplasty. Journal of the American Academy of Orthopaedic Surgeons; 9:4, 253-257.

13. McAuley CE, Steed DL, Webster MW. (1984). Arterial complications of total knee replacement. Archives of Surgery.; 119:8, 960-962.

14. Chikkanna JK, Sampath D, Reddy V, Motkuru V. (2015). Popliteal Artery Thrombosis after Total Knee Replacement: An Unusual Complication. J Clin Diagn Res;9(11): RJ01-RJ2. doi:10.7860/JCDR/2015/15434.6712

15. Green NE, Allen BL. (1977). Vascular injuries associated with dislocation of the knee. The Journal of Bone and Joint Surgery; Series A, 59:2, 236-239.

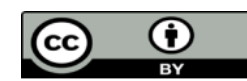

This work is licensed under Creative Commons Attribution 4.0 License

\section{To Submit Your Article Click Here: Submit Manuscript}

DOI: $10.31579 / 2690-1897 / 062$
Ready to submit your research? Choose Auctores and benefit from:

* fast, convenient online submission

* rigorous peer review by experienced research in your field

* rapid publication on acceptance

* authors retain copyrights

* unique DOI for all articles

* immediate, unrestricted online access

At Auctores, research is always in progress.

Learn more www.auctoresonline.org/journals/journal-of-surgical-casereports-and-images 